\title{
A memorable beginning, a rich history and a promising future
}

\author{
Robert B Kalina
}

I:

t was 25 years ago when I welcomed two distinguished guests into my one-man office filled with recycled furniture - Dr ABR Thomson and Dr CN Williams, co-Editors-in-Chief, the CAG President and Past President. They had considerable doubts about the abilities of the Publisher sitting across from them whose only claim to fame was one (albeit successful) cardiology journal. The company name had just been changed from Canadian Cardiology Publications to Pulsus Group, and their tongue-in-cheek suggestion was to change it again to 'Peristalsis'. It was a memorable beginning for The Canadian Journal of Gastroenterology.

We are pleased to say that despite its inexperienced publisher, the Journal has survived and, indeed, prospered and grown. Today, it is a top-notch Canadian journal - read, respected and appreciated around the world. This accomplishment did not happen overnight, and it certainly did not take place without the leadership and assistance of several individuals and organizations. It took Drs Thomson and Williams 10 years to firmly establish the base upon which subsequent Editors-in-Chief continued to build and expand - each adding their unique characteristics. Dr Lloyd Sutherland, an expert in clinical trials, continued to focus on and improve the Impact Factor. Dr Paul Adams, an internationally recognized expert in many areas, particularly hemochromatosis and iron overload, raised the bar on many fronts working with his talented team in London, Ontario. The current Editor-in-Chief, Dr Subrata Ghosh, previously an Associate Editor with Gut, will move us in yet another direction with new enthusiasm and departments undoubtedly taking it to even greater heights.

The Canadian Journal of Gastroenterology was adopted by the Canadian Association of Gastroenterology as its official publication in 1994. In 2001, we welcomed the endorsement of the Canadian Association for the Study of the Liver. Pulsus Group gives a percentage of advertising revenues back to the Societies in support of their programs, and it has been a remarkably symbiotic relationship that we hope will continue for many years to come. We have worked hard, and will celebrate our remarkable achievement together over the course of the year.

This feat is all the more remarkable given the fact that we are in the most challenging period in the history of medical publishing in Canada. We sincerely thank the readers, authors, reviewers, Editorial Board members and the pharmaceutical companies that have recognized the importance of supporting Canadian peer-review medical research and supported The Canadian Journal of Gastroenterology with their advertising. 


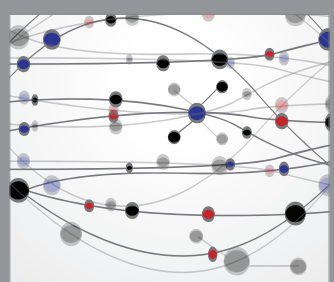

The Scientific World Journal
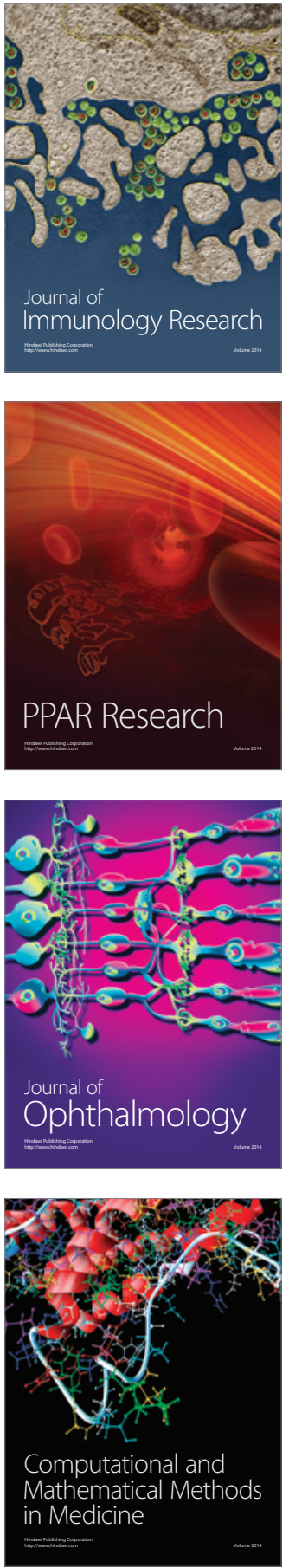

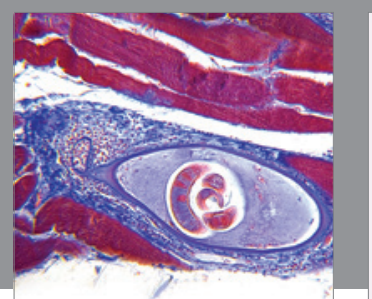

Gastroenterology Research and Practice

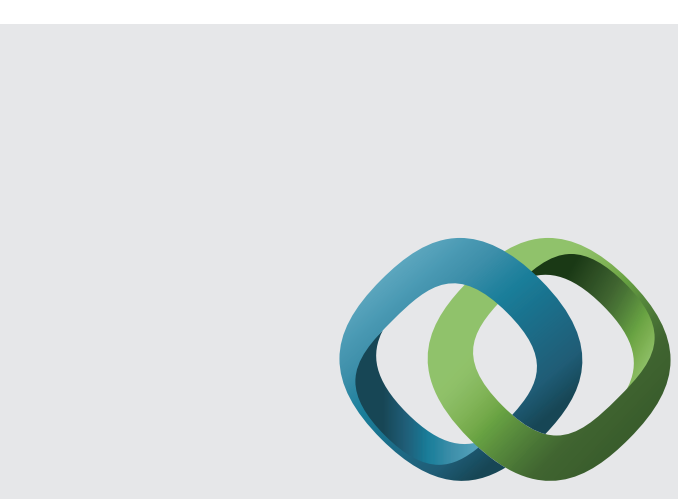

\section{Hindawi}

Submit your manuscripts at

http://www.hindawi.com
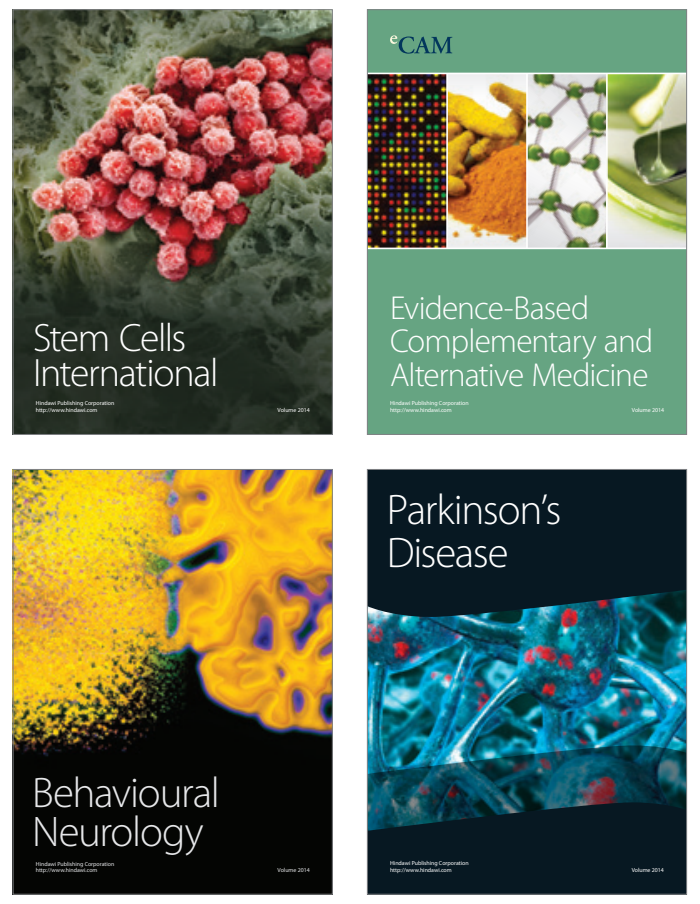
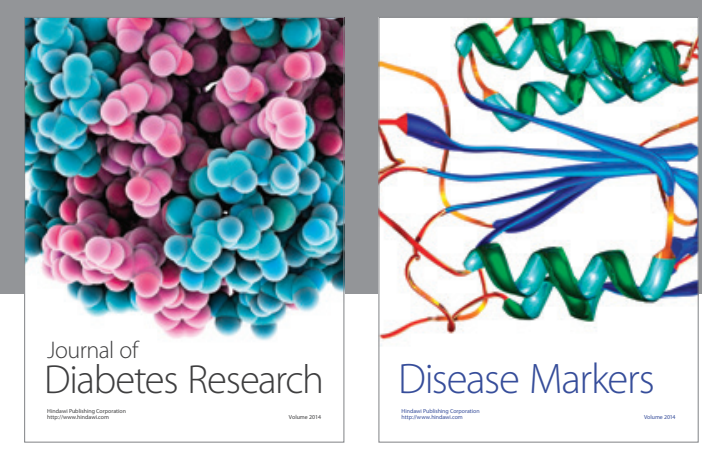

Disease Markers
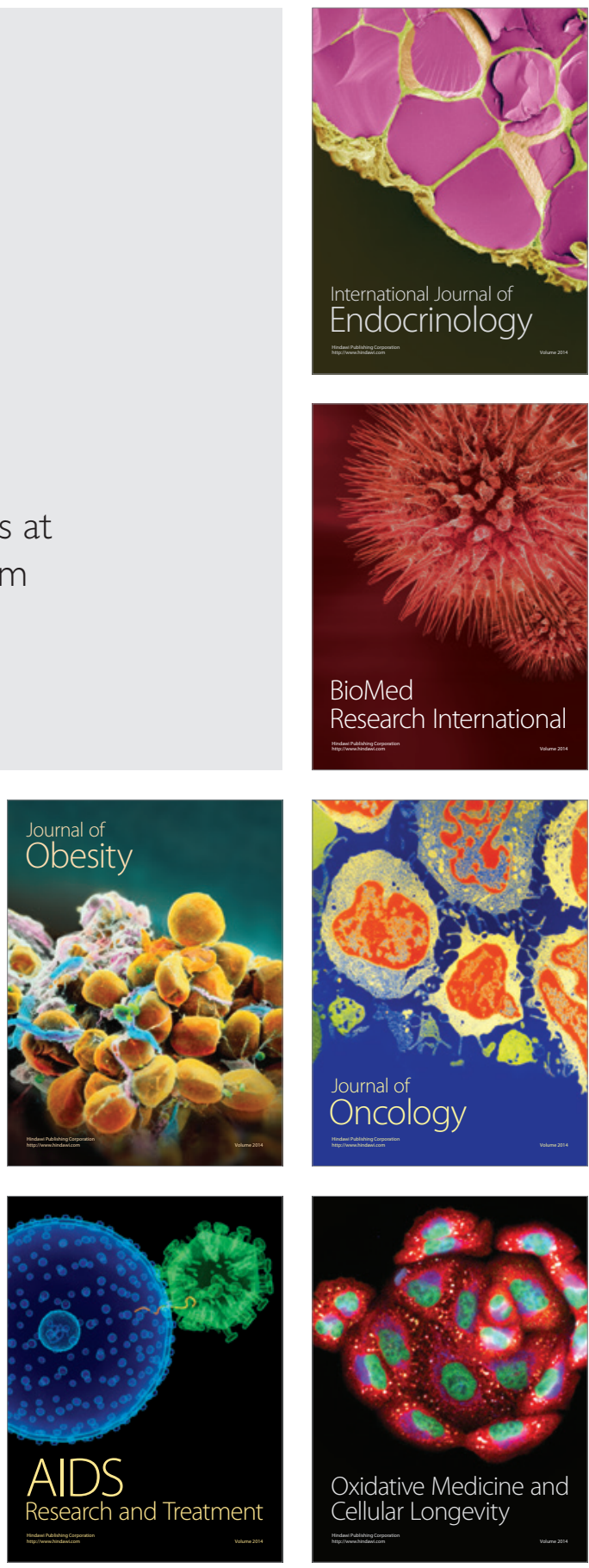